\title{
Anticancer Effects of LBA-ST Yogurt Supernatant on HeLa Cells via Heat Shock Protein 27 Decrease In Vitro
}

\author{
Liziyyannida $^{1, *}$ and Wibi Riawan ${ }^{2}$ \\ ${ }^{1}$ Pharmacy Study Programme, Faculty of Medicine, Universitas Brawijaya, Malang, Indonesia \\ ${ }^{2}$ Biochemical and Biomolecular Department, Faculty of Medicine, Universitas Brawijaya, Malang, \\ Indonesia
}

\begin{abstract}
Heat Shock Protein 27 (Hsp27) is overexpressed in cervical cancer as a response to stress conditions. Hsp27 overexpression increase invasion, migration, and adhesion pathways of cancer cells. The Yogurt supernatant contains Short-Chain Fatty Acids (SCFA) include acetate, lactate, and butyrate which have anticancer activity. This study aimed to investigate supernatant of LBA-ST (Lactobacillusbulgaricus-acidophilus, Streptococcusthermophillus) Yogurt can decrease the expression of Hsp27 in HeLa culture cells. The mechanism on how supernatant yogurt inhibit invasion, migration, and adhesion was studied by immunocytochemistry. The data was then collected and analyzed using One-Way ANOVA. From this study, it can be concluded that the expression of proteins that play a role in invasion, adhesion, and migration of the Hsp27 was proven to be decreased $(p<0.05 \pm 0.005)$.
\end{abstract}

Keywords: HeLa cells, yogurt supernatant, Lactobacillus bulgaricus-acidophilus, Streptococcus thermophillus, Hsp27.

\section{INTRODUCTION}

The growth of abnormal cells in mucosal servix, exocervix, and endocervix known as cervical cancer (American Cancer Society, 2012). Cervical cancer has the second highest prevalence of cancer in woman following breast cancer. Human papilloma virus (HPV) is the main cause in cervical cancer (Castellsagué, 2012).

Vaccination, surgery, radiotherapy, and chemotherapy are the common therapies in the cervical cancer. Those therapies has serious side effects, and promising solution has not been established yet. Moreover, vaccination still can not be implemented in every country because of the high cost and limited availability (Goldie, et al., 2005).

The fermentation products are recommended as the alternative therapy (Rahman, 2013), because of their multiple mechanisms of action, high safety, and the continuity of production (McFarldan, 2009). Yogurt is the product obtained from the milk fermentation by the lactic acid bateria. ShortChain Fatty Acids (SCFAs) such as butyrate, acetate, and lactate are the dominant metabolite compound in yogurt Lactobacillus bulgaricusacidophillus and Streptococcus thermophillus (LBA-ST) and were reported to have anticancer activity (Hara and Fergus, 2007).

Those metabolites could have antimutagenic, antioxidative, and anticarcinogenic effect, along with the modulation of immune system (Wollowski, et al., 2001). In the identification of cervical cancer marker, Hsp27 is known as the critical role in the development of invasion, migration, and cell adhesion (Patel, et al., 2002; Rerole, et al., 2010) This study aim was to investigate LBA-ST yogurt supernatant in the decrease of Hsp27 expression on HeLa culture cells to inhibit the invasion, migration, and adhesion.

\footnotetext{
*Corresponding author email: lizzyasmakinasih@gmail.com
} 


\section{MATERIALS AND METHODS}

\section{Fermentation of LBA - ST Yogurt (Lactobacillusbulgaricus-acidophilus, Streptococcusthermophillus)}

One litre of milk was heated in the temperature of $82-100^{\circ} \mathrm{C}$. Then the temperature was cooled down to $42-44^{\circ} \mathrm{C}$. As many as $5 \mathrm{gr}$ of yogurt stater (yoguormet t.m) containing LBA-ST were dissolved in a cup of the milk and then homogenized well by adding a litre of milk. Incubation were done in the temperature of $4^{\circ} \mathrm{C}$ for 4.5 hours or untill the $\mathrm{pH}$ reach $4-5$. Fermentation was then stopped by storing the yogurt in the refrigerator prior to usage (Yogourmet, 2014).

Preparation of supernatant, pellet, and whole LBA-ST yogurt

As many as four falcons of $50 \mathrm{~mL}$ LBAST Yogurt were centrifuged for 15 minutes in $4000 \mathrm{rpm}$. The supernatant were separated from the bacteria pellet by filtration with Whatman paper. The storage were done in the temperature of $4^{\circ} \mathrm{C}$.

\section{HeLa Cell Culture}

HeLa cells were obtained from Laboratorium Pengujian dan Penelitian Terpadu (LPPT), Universitas Gadjah Mada, Yogyakarta. HeLa cells were cultured in RPMI 1640 media supplemented with $10 \%$ (v/v) FBS and non essential amino acids. Cells were counted by haemocytometer. Cells were harvested with Trypsin-EDTA, and centrifuged in $1500 \mathrm{rpm}$ for 8 minutes. The supernatant was removed and the pellet was resuspended in the added culture media. Cells were cultured in well plates and were incubated in the temperature of $37^{\circ} \mathrm{C}, 5 \% \quad \mathrm{CO}_{2}$, and $100 \%$ humidity.

\section{Hsp27 Immunocytochemistry}

As many as $5 \times 10^{4}$ cells $/ 1000 \mu \mathrm{L}$ HeLa cells supension were cultured with RPMI 1640 culture media and distributed in 24-well plate on the cover slips and incubated for 24 hours. After the cells were confluent, cells were treated by the supernatant of LBA-ST yogurt with the concentration of 10,20, and $40 \%(\mathrm{v} / \mathrm{v})$.
As for the control group, $1000 \mu \mathrm{L}$ of culture medium was added.

After 24 hours incubation, the cover slips were washed by cold PBS 2 times, fixed by cold methanol for 15 minutes, and washed by the PBS once. Then the hydrogen peroxide as the blocking solution was added, followed by incubation for 10 minutes. The immunocytochemistry was done by adding 400 $\mu \mathrm{L}$ Hsp27 monoclonal antibody in 1:200 dilution. The incubation was done for 1 hour, then the cover slips were washed by the PBS. Biotinylated universal secondary antibody was then added. PBS were used to wash the cells before and after the incubation by streptavidin peroxidase enzyme. The incubation was done for 10 minutes. The chromogene substrate diaminobenzidine were added, continued with incubation for 10 minutes. Next, cells were washed by aquadest. As the counterstain, Meyer haematoxylin was added prior to incubation for 3 minutes, followed by washing using aquadest. The coverslips were then dried up by xylol and ethanol. The coverslips were placed on the microscope slides and mounted with entellan. Cells were observed and the Hsp27 expression were counted using the microscope.

\section{Data Analysis}

The data were analyzed statistically by the SPSS 16 for Windows 7 program. The normality and homogenity study were done first, and the analysis of the data were done by ANOVA ( $p=0.05$ and $\alpha=0.05)$.

\section{RESULTS AND DISCUSSION}

\section{The effects of LBA-ST yogurt supernatant to the expression of Hsp27}

The aim of this study was to investigate the effects of LBA-ST yoghurt in the decrease of Hsp27 expression on HeLa cells. The entire result of this study showed that LBA-ST yoghurt has anticancer on HeLa cells. Anticancer activity showed by the data of the expression of Hsp27 in the Control cells (Fig. 1) and the Hsp27 expression index by the treatment of LBA-ST yoghurt supernatant (Fig. 2). 


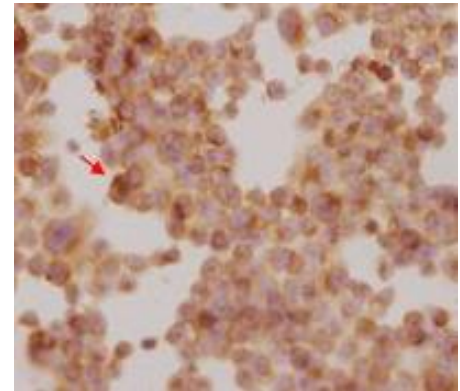

(A)

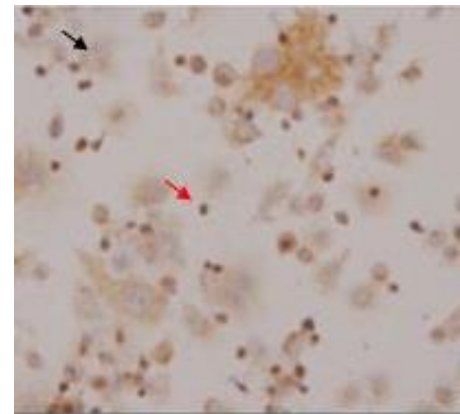

(C)

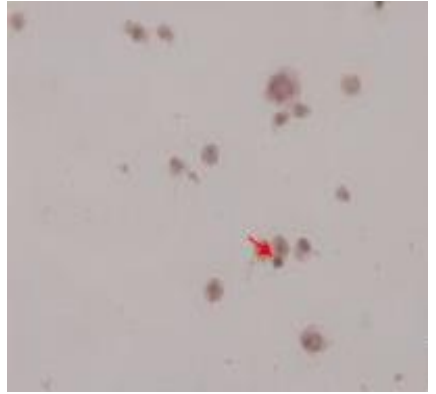

(B)

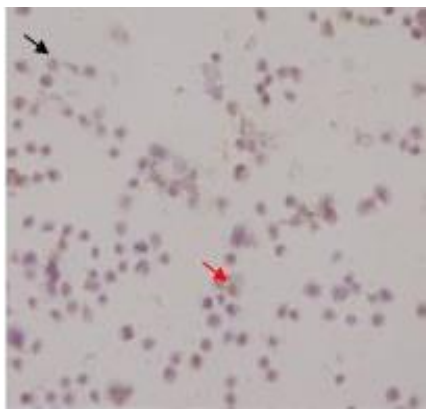

(D)

Figure I. The expression of Hsp27 in the control cells (A), the treatment of supernatant of $10 \%(\mathrm{v} / \mathrm{v})$ (B), $20 \%(v / v)(C)$, and 40\% (v/v) (D) LBA-ST yogurt. Incubation was done for 24 hours, and the expression of Hsp27 in cells lead to the increase of the quantity of color and morphological changes in HeLa cells (400x magnification), decreased expression $(\rightarrow)$, overexpression $(\rightarrow)$. Distribution of cells and different cell sizes were obtained in the same magnification.

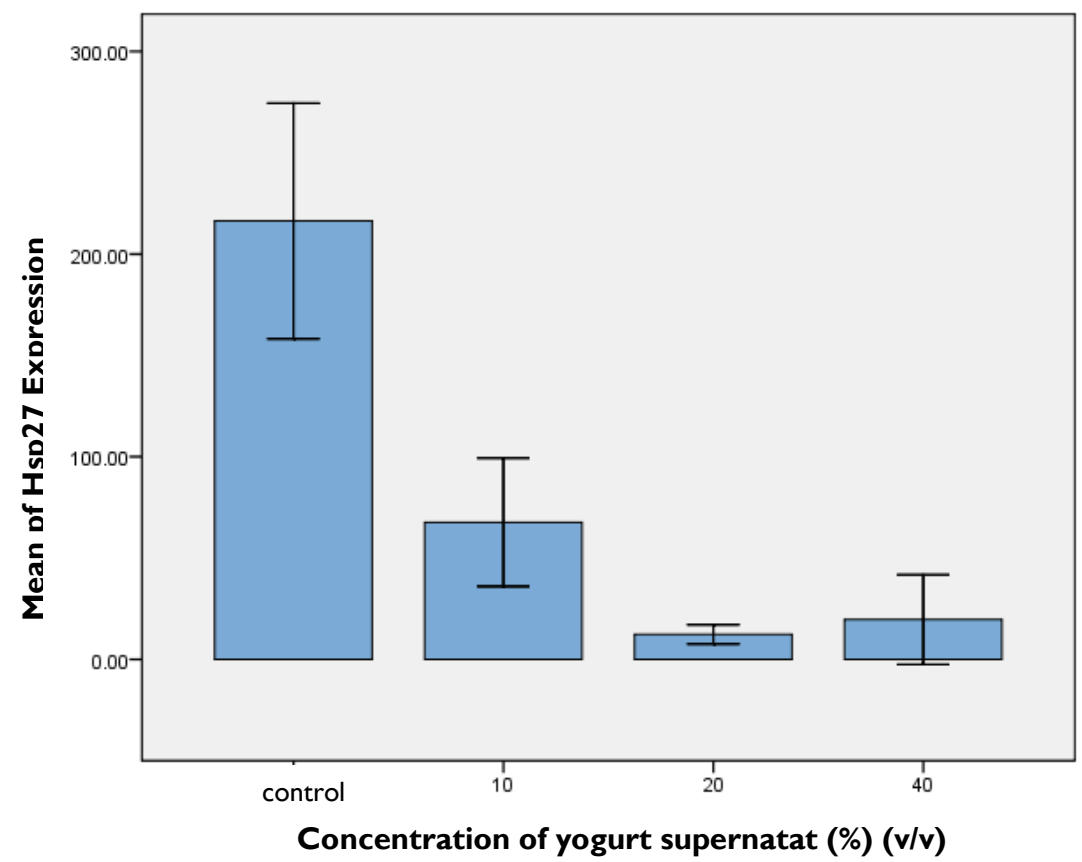

Figure 2. Hsp27 expression index by the treatment of LBA - ST yogurt supernatant in the concentration of $10 \%, 20 \%$, dan $40 \%(\mathrm{v} / \mathrm{v})$ compared to the control. The graph of reduction in Hsp27 expression were done by the data analysis by ANOVA $(p<0.05 \pm 0.005)$. 
The testing of the anticancer mechanism in the cervical cancer can be done by the observation of Hsp27 expression. In this study, Hsp27 expression in HeLa cells were decreased by the treatment of supernatan of yogurt LBA significantly compared to the control $(p<0.001)$. The highest reduction of Hsp27 expression was obtained by the treatment of supernatan of yogurt LBA in the concentration of $20 \%(\mathrm{v} / \mathrm{v})$. Based on the result of this study, LBA-ST yogurt supernatant may inhibit the proliferation, migration, and invasion of cervical cancer cells, and also induce apoptosis.

\section{ACKNOWLEDGEMENT}

We would like to say thank you to Mrs. Husnul Khotimah S.Si., M Kes., Mrs. Yuli, S.Si, Mrs. Arini, S.Si, Erita Rahmani, and Desie Suci Permata Sari for the support of this study and give the suggestion and analyze the data.

\section{REFERENCES}

American Cancer Society, 2012, Cervical Cancer Detailed Guide, Atlanta: American Cancer Society.

Castellsagué, X., Laia B., Laia A., Mireia D., Silvia S., Xavier F, 20I2, The Epidemiology of Cervical Cancer, In:
HPV and Cervical Cancer, n.p: n.p., Pp.63-83.

Goldie, S.J., Kuhn, L., Denny, L., Pollack, A., Wright, T.C., 200I, Policy Analysis of Cervical Cancer Screening Strategies in Low Resource Seetings: Clinical Benefits and Cost Effectiveness, JAMA, 285(I4), $3|07-3| I 5$.

O'Hara, A.M. and Shanahan, F., 2007, Mechanisms of Action of Probiotics in Intestinal Diseases, The Scientific World Journal, 7, 3 I-46.

McFarldan, 2009, Regulation of short-chain fatty acid production, Proceed. Nutr Soc., 62(I), 67-72.

Patel, V., Aldridge, K., Ensley, J.F., Odell, E., Boyd, A., Jones, J., et al., 2002, Lamininy2 Overexpression in Head and Neck Squamous Cell Carcinoma, Int. J Cancer, 99(4), 583-588.

Rahman, M., 2013, Medical Application of Fermentation Technology, Adv. Mater. Res, 8 I 0, I27-I57.

Rerole, A.L., Joly, A.L., Thuringer, D. and Garrido, C., 2010, Hsp70 and Hsp27: Emerging Targets in Cancer Therapy, Apoptosome, 169-202.

Wollowski, I., Rechkemmer, G. and PoolZobel, B.L., 200I, Protective Role of Probiotics and Prebiotics in Colon Cancer, Am. J. Clin. Nutr., 73(Suppl 2), 45 IS-455S. 
